\title{
SNOW STRATIGRAPHIC RECORD AT SOUTH POLE: POTENTIAL FOR PALEOCLIMATIC RECONSTRUCTION
}

\author{
by \\ E. Mosley-Thompson, P.D. Kruss and L.G. Thompson, \\ (Institute of Polar Studies, Ohio State University, Columbus, Ohio 43210, U.S.A.) \\ M. Pourchet \\ (Laboratoire de Glaciologie et Géophysique de l'Environnement du C.N.R.S., B.P. 96, \\ 38402 St.-Martin-d'Hères Cedex, France) \\ and P. Grootes
}

(Quaternary Isotope Laboratory, University of Washington, Seattle, Washington 98195, U.S.A.)

\begin{abstract}
An extensive investigation of the visible stratigraphy, microparticle concentration, liquid conductivity, oxygen isotopes and beta-radioactivity was conducted in pits excavated at Amundsen-Scott South Pole station. The objectives of the investigation were to assess the spatial representativeness of the geochemical and physical records preserved within the snow strata and to ascertain the temporal resolution which can be obtained from such ice-core records. Accurate interpretation of the time scale and reconstruction of climatic conditions from these time series requires (1) the analysis of as many stratigraphic parameters as possible and (2) the synthesis of data from a suite of cores in the study area. For periods of 10 a or less, regionally representative accumulation rates cannot be obtained from annual accumulation time series reconstructed at a single site. Although the microparticle concentrations, liquid conductivity and oxygen isotopic abundances all exhibit a seasonal cycle in the firn, the construction of an accurate time scale requires all three parameters in conjunction with the beta-radioactivity. Absolute dating will be impossible for cores from South Pole where entire accumulation years may be missing. Nevertheless, for East Antarctica, where accumulation rates are low $\left(<0.1 \mathrm{~m} \mathrm{a}^{-1}\right.$ water equivalent), the good temporal resolution and the preservation of a distinct annual signal in some geochemical parameters makes the South Pole a very attractive site for deep ice-core drilling.
\end{abstract}

\section{INTRODUCTION}

A stratigraphic record of an ice core is truly representative of only the drill site and therefore the utility of the record preserved within an ice core is a function of (a) the degree to which the record at the drill site reflects that of the area (spatial representativeness) and (b) the maximum temporal resolution available from the preserved ice-core parameters (microparticle concentrations, oxygen isotopic abundances, liquid conductivities and beta-radioactivity). To investigate these problems a program of pit and shallow coring was initiated at the Amundsen-Scott South Pole station which is likely to be the focus of deep ice-core drilling in East Antarctica. Since 1980 two intermediate cores (201 and $336 \mathrm{~m}$ ) have been drilled at South Pole (Kuivinen and others 1982, Kuivinen 1983). The analysis of these cores includes microparticle concentrations (Mosley-Thompson and Thompson 1983), oxygen isotopic abundances, conductivities and $\mathrm{CO}_{2}$ concentrations (Stauffer and Schwander 1983).

\section{THE STRATIGRAPHIC RECORD}

During November and December 1982 a series of pits was excavated and shallow cores were drilled to define the maximum temporal resolution to which deeper cores may be dated and to assess the degree to which the accumulation record from a single core represents true climatic trends in the vicinity of South Pole. This paper will focus upon the period from 1971 to 1982 using data from two pits as well as measurements of accumulation from stake networks. The primary pit (P1) was located about $4 \mathrm{~km}$ from the station along grid $128^{\circ}$ (Fig.1), downwind from, but in close proximity to, the clean-air sector, thus reducing the chance of vehicle contamination. Pits 2 and 3 (P2 and P3) were positioned approximately $0.5 \mathrm{~km}$ from pit 1 . Pit 4 (P4), located 1.5 $\mathrm{km}$ from P1, was excavated at a stake in line I (Fig.1) of the Institute of Polar Studies accumulation stake network (established in 1978 by I Whillans personal communication).

All pits were excavated by hand to ensure clean vertical walls but the stratigraphic mapping procedure employed was slightly different from that used in previous investigations (Gow 1965, Koerner 1971). Neither hardness nor grain size was measured in detail, nor were seasonal changes in density identified, although closely spaced density measurements were made down each pit wall. During the stratigraphic mapping special attention was focused upon distinctive boundary features separating successive annual accumulation units. The details of the mapping procedure which resulted in an accuracy of $\pm 0.01 \mathrm{~m}$ are discussed elsewhere (Mosley-Thompson and others 1983). Vertical sequences of $0.02 \mathrm{~m}$ samples were collected for microparticle, oxygen isotope, liquid conductivity and beta-activity analyses. Each sample may be precisely located on the stratigraphic map so that the relationship between a specific snow parameter and the visual stratigraphic features may be assessed.

\section{VISIBLE STRATIGRAPHY}

Visible stratigraphy features preserved within firn were first observed in Antarctic firn by Scott (1905) and later in Greenland firn by Sorge (1935) who confirmed that summer and winter firn exhibited different characteristics. Winter deposits were fine-grained and dense while the summer deposits were coarse-grained and less dense. In a thorough investigation of pit stratigraphy at Maudheim, Antarctica, Schytt (1958) reported the most conspicuous feature to be the metamorphosed strata underlying the fine-grained firn 


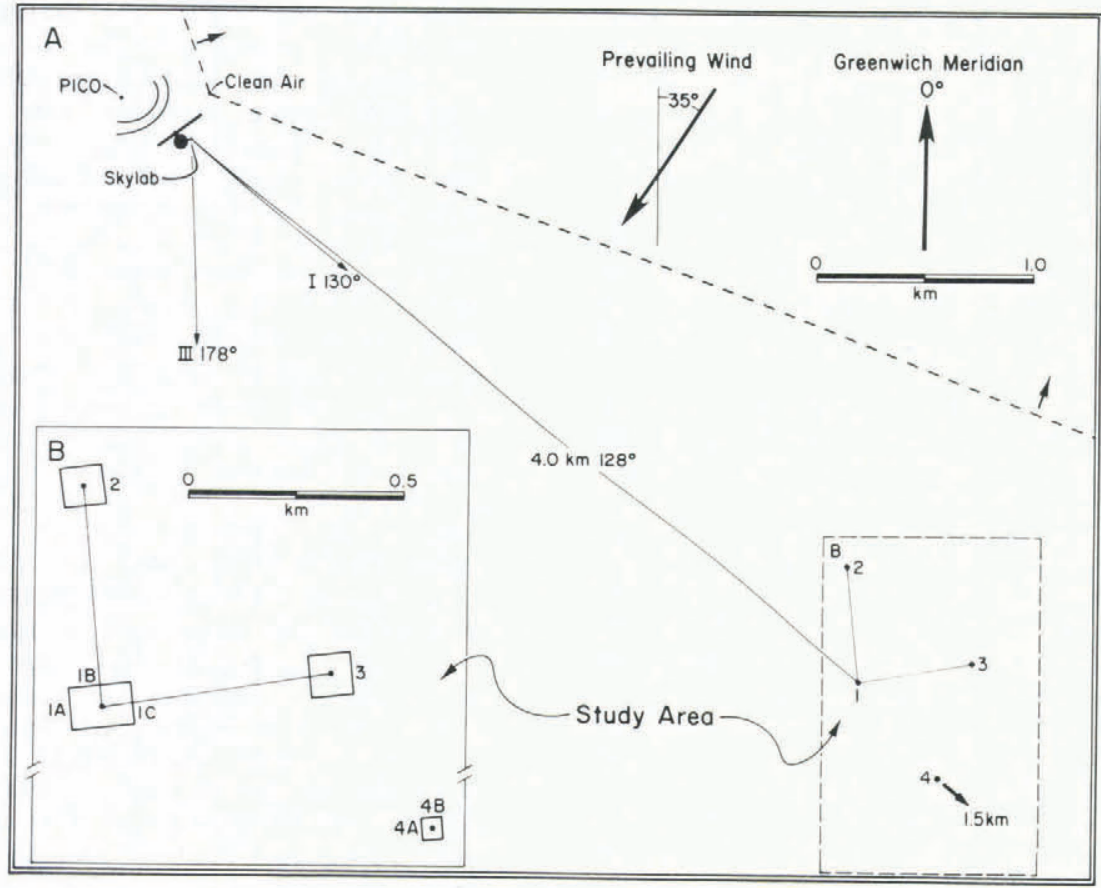

Fig.1. Map of Amundsen-Scott South Pole station illustrating the location of the pit study area, the Whillans accumulation stake network (lines I and III), the clean air quadrant (enclosed by dashed lines) and prevailing wind direction. Inset B shows orientation of the pit walls.

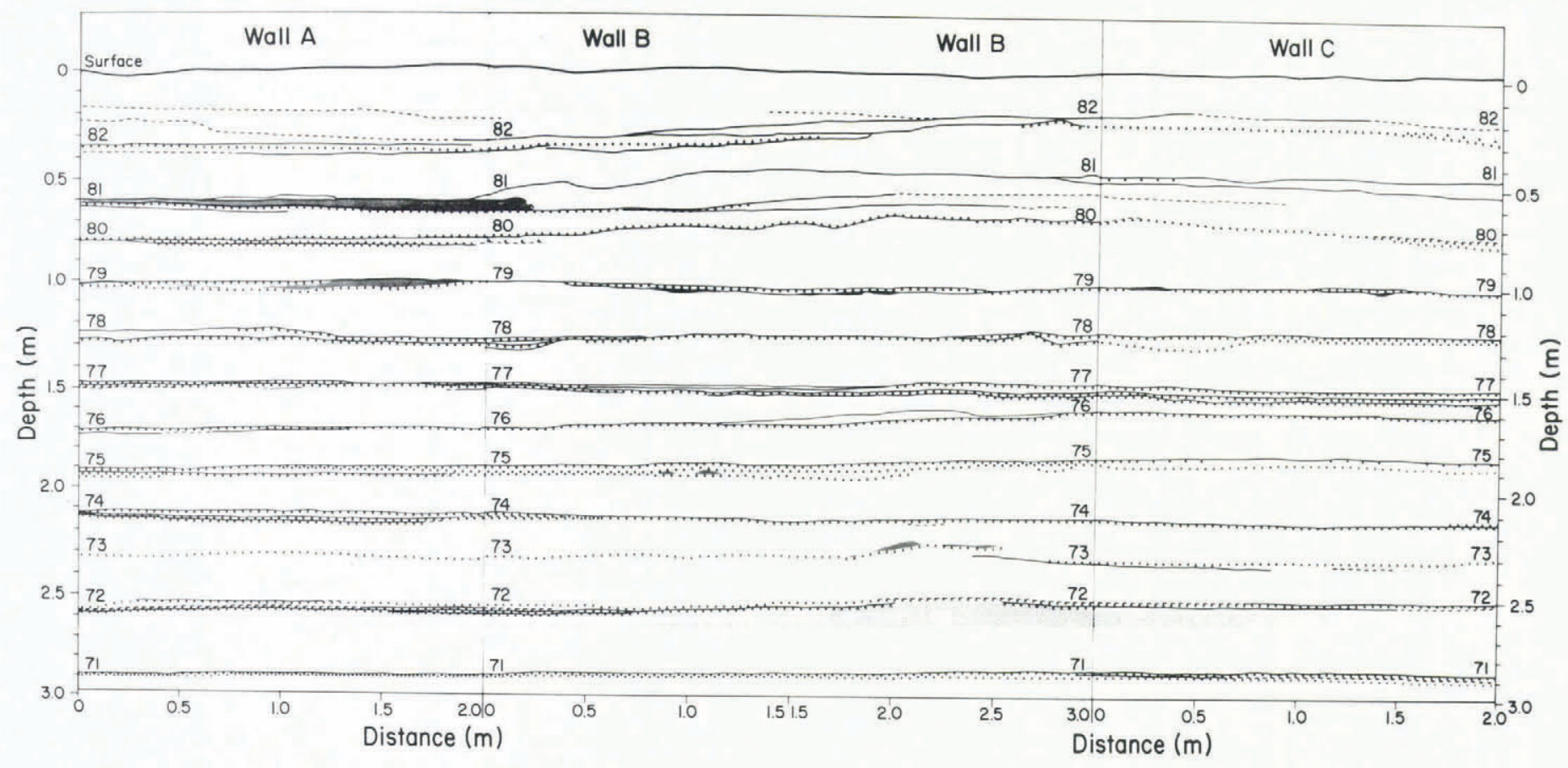

\section{Stratigraphy of Pit I, South Pole Station \\ Nov., 1982

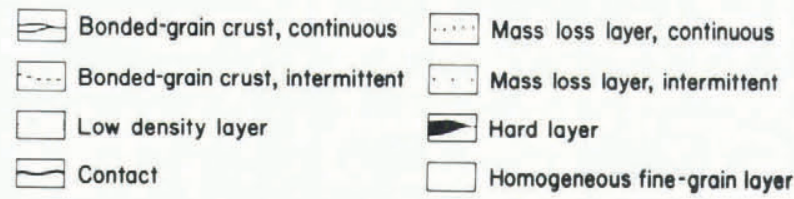

Fig.2. The stratigraphic map of pit 1 which had a depth of $3 \mathrm{~m}$. Parallel walls $\mathrm{A}$ and $\mathrm{C}$ are $2 \mathrm{~m}$ long and perpendicular to wall $B$ which is $3 \mathrm{~m}$ long. The legend illustrates the specific features of the stratigraphy which are discussed in the text. 
layers. Schytt was reluctant to call these features depth hoar, a term commonly applied to intensely metamorphosed layers within temperate glaciers which are attributed to high temperatures and steep temperature gradients (Bader and others 1939). Nevertheless these features, interpreted as highly metamorphosed summer surfaces, have provided the basis for the interpretation of annual stratigraphic units within Antarctic firn (Gow 1965, Koerner 1971, Jouzel and others 1983). The first evidence that "depth hoar" layers were an annual feature resulted from the excavation of pits at South Pole accumulation stakes (Gow 1965) which provided direct comparison of actual accumulation measurements with stratigraphic features preserved within the firn.

A primary physical process responsible for the development of stratigraphic features within Antarctic firn is metamorphism due to the temperature gradient and the associated transfer of vapor (Taylor 1971, Colbeck 1983). Vapor transfer and resulting crystal growth or loss are directly linked to the formation, preservation and/or destruction of annual chemical and physical signals within the firn. An extensive discussion of these processes is outside the scope of this paper in which we examine the temporal and spatial variability of the annual accumulation signal using visible stratigraphic features, geochemical profiles and measurements at accumulation stake networks.

Figure 2 illustrates the stratigraphy of an area 21 $\mathrm{m}^{2}$ along three walls of pit $1(2 \mathrm{~m}$ wide, $3 \mathrm{~m}$ long and $3.2 \mathrm{~m}$ deep). Walls $\mathrm{A}$ and $\mathrm{C}$ are parallel, and wall $\mathrm{B}$ is perpendicular to these walls. The most common stratigraphic feature in terms of areal coverage are the horizontally-continuous, homogeneous, fine-grained layers. The description "essentially homogeneous" is used cautiously because within-layer variations in grain size and hardness were observed, but not considered major features within the context of this project. Several prominent features such as the continuous, low-density, coarse-grained layer at $\sim 2.6 \mathrm{~m}$ depth on all walls, (Figure 2) were recorded.

The identification of the annual accumulation units was most critical to the objectives of this investigation and therefore the boundary features were very closely examined. These boundaries between successive annual units are thought to form in the fall (Gow 1965) and generally consist of a thin $(\sim 0.002 \mathrm{~m})$ bonded-grain crust and associated thin (few centimeters or less) layer, or layers, of mass loss. These mass loss layers, analogous to strata previously identified as depth hoar, have as the central feature a layer only a few millimeters thick which exhibits extremely low densities. The regions adjacent (above and below) to this very low density zone are characterized by larger crystals, large inter-grain cavities and low densities. The mass loss layer complex is usually bounded on the upper surface by a thin continuous bonded-grain crust which sometimes is present underneath the layer as well. The lateral continuity of these boundary features is the most striking feature of South Pole stratigraphy (Giovinetto and Schwerdtfeger 1966).

Close inspection of the stratigraphy of pit 1 (Figure 2) reveals large variations in layer thickness over small distances and from year to year, as illustrated by the horizontal variations in thickness of the 1979-1980 and 1976-1977 units. The 1976-1977 unit is twice as thick in wall A as in wall C. Such variability in the thickness of the annual layer over short distances makes it impossible to attribute climatic or meteorological significance to a year of higher or lower accumulation as reconstructed from a single site. The 1976-1977 unit is wedge-shaped, suggesting differential scouring (deflation) or deposition probably in association with small sastrugi.

The control of topography upon mass accumulation is well-documented (Black and Budd 1964, Gow and Rowland 1965, Benson 1971, Mosley-Thompson and Thompson 1982). Both large-scale (wavelength 5 to 30 $\mathrm{km}$ ) waves or dunes and small-scale (randomly scattered) sastrugi may control the spatial distribution of accumulation. The larger dunes may affect the accumulation site for many years $(>20$ a) while smaller sastrugi (amplitude $\sim 0.40 \mathrm{~m}$ ) may persist for only a single year. At South Pole the sastrugi produced during the winter accumulation period are slowly leveled over the summer by sublimation-deflation processes (Gow 1965). The entire sequence from 1971 to 1982 (Fig.2) is only $0.09 \mathrm{~m}$ thicker in wall $\mathrm{C}$ than in wall A suggesting that over this accumulation period small-scale undulations did not differentially control accumulation. Short periods of lower mass balance are generally followed by higher accumulation as the surface relief is smoothed by the filling of troughs (Fig.2). For the period from 1971 to 1982 the average accumulation in water equivalent (applying densities measured in pit) calculated for seven profiles $1 \mathrm{~m}$ wide along all three walls of pit 1 is $8.6 \mathrm{~mm} \mathrm{a}^{-1}$ with a minimum of 8.2 and a maximum of $8.7 \mathrm{~mm} \mathrm{a}^{-1}$. These data suggest that an averaging interval of 10 a may be sufficient to obtain an average annual accumulation estimate representative of a small area. The degree to which this 10 a average reflects regional conditions will be assessed in a subsequent paper now in preparation*.

The mapping of extensive areas of pit wall made it possible to examine the frequency of occurrence of very thick or multiple mass loss (depth hoar) layers and to assess their relationship to years of missing accumulation (hiatus years). This is a very critical issue for the reconstruction of paleoclimatic sequences. Gow (1965) was the first to suggest that thick-depth hoar layers reflected a period of "non-accumulation" or an hiatus year. Excavation of a pit at an accumulation stake (Gow 1965: fig.2) provided what he considered evidence that a thick-depth hoar layer may be associated with an hiatus year. However our investigations revealed that a thick mass loss layer does not necessarily reflect a year of zero accumulation.

Examination of the stratigraphy in pit 1 reveals numerous thick and multiple mass loss layers many of which appear to be associated with the formation of a mass layer on top of drif $\mathrm{t}$ which has filled a depression overlying an earlier mass loss layer (e.g. 1978-79 and 1973-74 in wall A). Other thick mass loss layers (e.g. 1975, wall B) are not mass loss layer/bonded-grain crust $(\mathrm{m} 11 / \mathrm{bgc})$ complexes but are one thick mass loss layer topped by the crust. The 1977 fall horizon consists of a triple complex of $\mathrm{mll} / \mathrm{bgc}$ in wall $\mathrm{C}$ but, if the horizon is traced along wall $\mathrm{B}, 3 \mathrm{~m}$ away in wall $\mathrm{A}$ it gradually merges into a single $\mathrm{mll} / \mathrm{bgc}$ feature. Therefore the interpretation of the 1977 thick mass loss layer as indicative of a missing year would appear incorrect. Carrying this argument slightly further, we may consider that if wall $C$ had been several meters further upwind (right side of diagram) the 1976-77 unit might have pinched out (merged) in which case the interpretation of a missing year would have been correct. These data confirm the necessity to expose large areas of pit wall to ensure proper interpretation.

To further examine the relationship between mass balance inferred from visual stratigraphy and accumulation measured at stakes, pit 4 was excavated at an accumulation stake (Fig.1) in a network emplaced in November 1978 (I Whillans personal communication). The results are presented in Figure 3. Walls A and B are perpendicular and intersect at the stake. The height of the snow surface was measured on the stake at the dates indicated while the date of the stratigraphic horizon appears along the depth axes. The stratigraphy was mapped identically to that in pit 1 . The intermittent crust in the 1982-83 unit is a storm horizon typically observed in the upper annual unit but which is not preserved in older firn. The thick sequence of $\mathrm{mll} / \mathrm{bgc}$ in wall B (1981) appears to have resulted from filling in

*Mosley-Thompson E, Kruss P D, Thompson L G, Pourchet M, Gow A J Reconstruction of climatically significant accumulation time series at the South Pole from shallow cores. 
Stratigraphy of Pit 4, South Pole Station

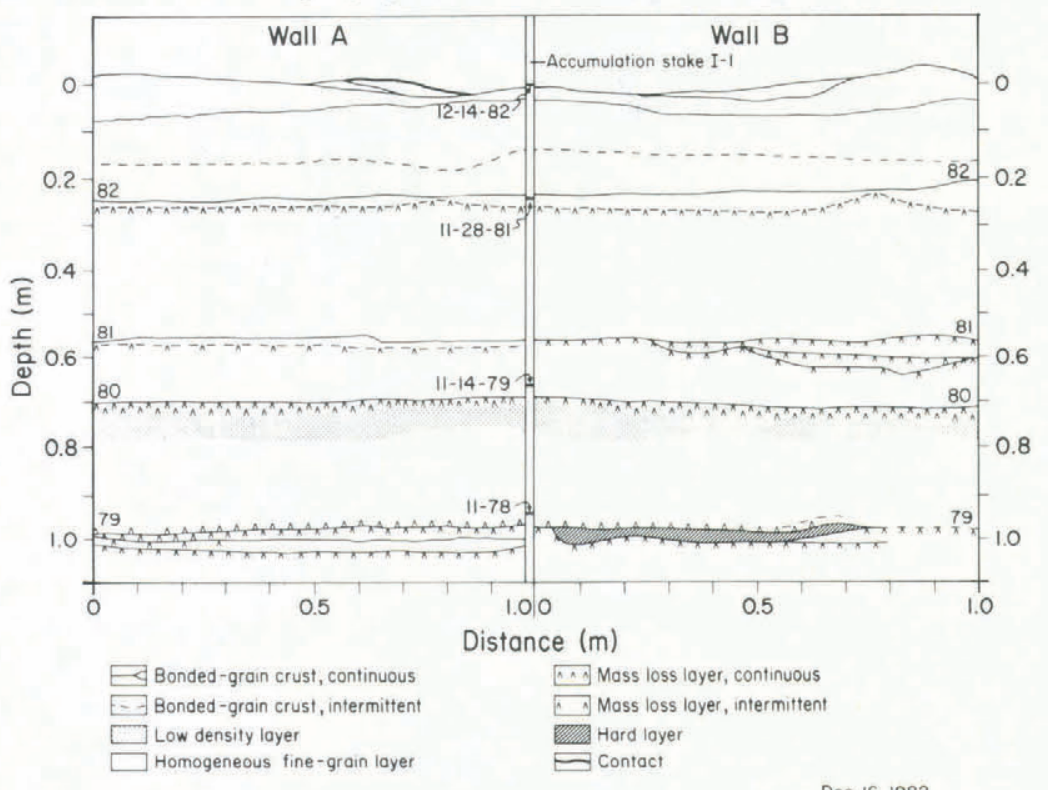

Dec. 16,1982

Fig.3. The stratigraphic map of pit 4 excavated at a stake in line I (Fig.1) of the Whillans stake network. Walls $A$ and $B$ are perpendicular, intersecting at the accumulation pole. The marks on the stake reflect the position of the surface on the given date and the dates along the depth axes mark the fall surfaces (annual boundary features) as inferred on the basis of the visual stratigraphy. The legend illustrates the specific features which are discussed in the text.

along the side of a sastrugi. If only a small vertical area of wall had been excavated at that point and no accumulation been measured at the stake, a missing year may have been incorrectly inferred. Over the period from November 1978 to December 1982 the measurements at all 23 poles in the Whillans accumulation network showed no years of missing accumulation. A detailed study of accumulation measured along several networks at "old" South Pole station is in progress and preliminary inspection indicates that the frequency of missing years is quite low $(<7 \%)$ when differences are calculated from consecutive spring or fall horizons.

The validity of the above discussion hinges upon the accuracy with which the stratigraphic sequences have been dated. To confirm the stratigraphic dating and to assess the dating utility of other geochemical and physical signals preserved within the ice sheet, samples were analyzed for beta-radioactivity, microparticle concentrations, liquid conductivity and oxygen isotopic abundances.

\section{BETA-RADIOACTIVITY MEASUREMENTS}

Artificial beta-radioactivity measured in Antarctic snow (Crozaz 1969, Jouzel and others 1979, Pourchet and others 1983) generally exhibits two prominent horizons (1955 and 1964-65) resulting from the testing of thermonuclear devices. These time horizons are preserved within the firn, providing an independent check upon the dating of upper layers. None of the pits in this study was deep enough to reach the $1964-65$ horizon but the $13 \mathrm{~m}$ cores drilled behind a wall of each pit contain approximately 60 a of accumulation. Beta measurements for the core behind wall C of pit 1 place the 1955 horizon at $6.12 \mathrm{~m}$ and the 1965 horizon at $4.25 \mathrm{~m}$ and confirmed the earlier dating of that profile using the microparticle and conductivity variations in both the pit wall (1982 to 1971) and the core (1971-1955). The beta measurements for a complete vertical sequence of $0.02 \mathrm{~m}$ samples collected along wall $\mathrm{C}$ of pit 1 are presented in Figure 4 (profile B). The beta profile from a 1978 pit (Pourchet and others 1983) is presented on the left (profile A). The dates of the fall horizons (Fig.4) are inferred independently from individual pit stratigraphy.
Specific peaks may not necessarily correlate with depth as individual accumulation units will vary in thickness at the two sites. Even the most pronounced beta horizons (1955 and 1965) are not always well marked and are sometimes missing or hardly visible (Lambert and others 1977) due to removal or redistribution of snow. The 1982 profile (B) goes back only to 1970 but both profiles show similar trends with a gradual decrease after 1972 with a modest increase in 1974-75 corresponding to 1974 French tests made at Mururoa (South Pacific). This same trend in beta-radioactivity was also measured in air samples at Dumont d'Urville (Lambert and others 1977: fig.1).

\section{MICROPARTICLE CONCENTRATIONS,} CONDUCTIVITY AND OXYGEN ISOTOPES

Samples for microparticle concentration and size distribution analysis were collected in a complete vertical sequence down the pit walls with a sample size of $0.02 \mathrm{~m}$ and with each sample precisely located on the stratigraphic map. The analysis of particulate concentrations in firn is difficult as firn is unconsolidated, easy to contaminate, and difficult to clean (Thompson 1977). When dealing with firn it is ideal to have a core from which the inner material can be extracted with a clean sampling device. Cores drilled from the surface were so unconsolidated in the upper meter that stratigraphic continuity could not be assured. Therefore samples were collected from the pit walls with a clean hand sampler and were placed in individual plastic bags. The microparticle analysis is conducted in a class 100 clean room using the Coulter Counter technique. The complete analysis procedure is described elsewhere (Thompson 1977).

The particulate concentrations in the pit samples were found to be higher than those in the cores drilled behind the pit walls. Three potential sources of contamination are the sampler, the bags and exposure of the pit wall to the air. The particulate profiles in the pit wall and the adjacent core were very similar in form but with higher concentrations in the pit samples. When the samples were returned it was discovered they had been subjected to steep temperature gradients during transportation as the original unconsolidated firn in each 


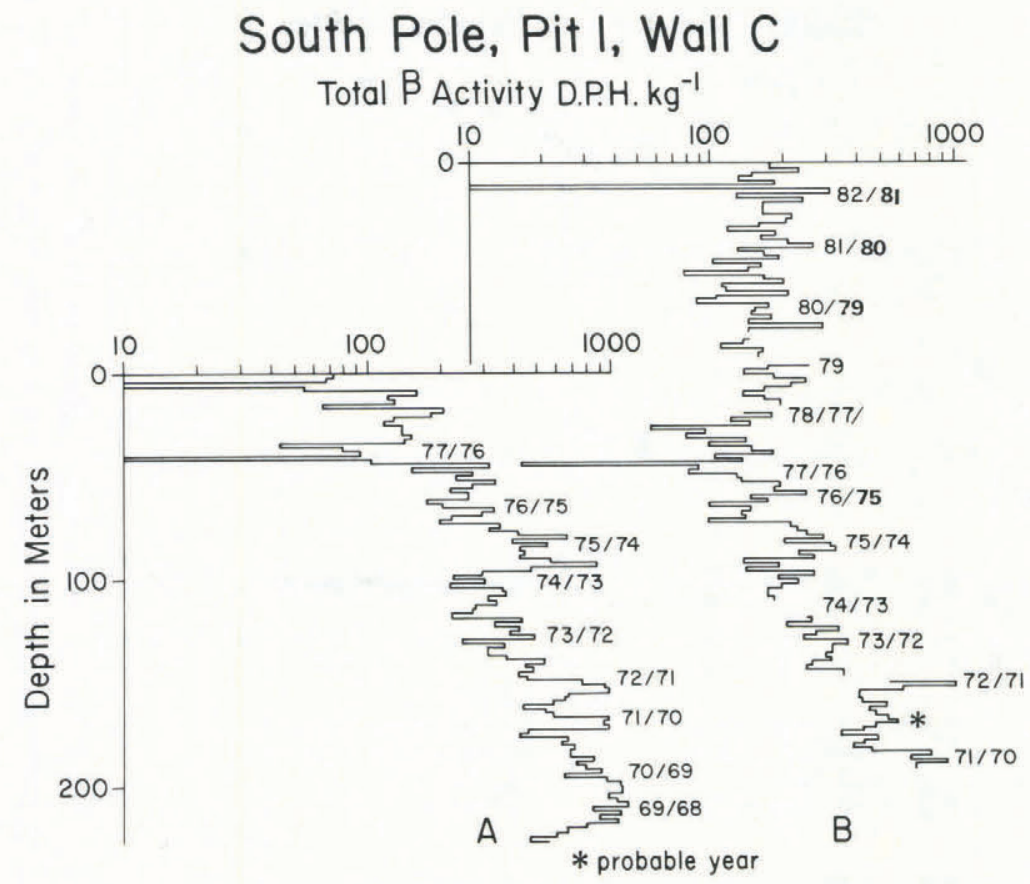

Fig.4. The beta-radioactivity in disintegrations $\mathrm{kg}^{-1} \mathrm{~h}^{-1}$ is presented for two South Pole pits. Profile A is from a 1978 pit (Pourchet and others 1983) excavated in the same general area as those in this study. Profile B samples were collected from wall C of pit 1 with a sampling size of $0.02 \mathrm{~m}$. The dates mark the annual boundary features independently determined from the visible stratigraphy in each pit.

bag was quite consolidated having experienced vapor transfer. To avoid any contamination from the bag walls the samples for microparticle analysis were removed from the center of each bag using a pre-cleaned hand sampler. The concentration of particles with diameters between 0.63 and $0.80 \mu \mathrm{m} \mathrm{ml} \mathrm{ml}^{-1}$ of liquid sample are presented for pit 1 walls $A$ and $C$ in Figures 5 and 6, respectively. Similar trends in the particulate profiles from walls $A$ and $C$ rule out the probability of random contamination.

Residual material from the bagged microparticle samples was used for liquid conductivity which was measured in the clean room using a Beckman conductivity bridge with a cell constant of $0.001 \mathrm{~m}^{-1}$ and standardized temperature of $20^{\circ} \mathrm{C}$. These conductivities $\mathrm{C}$ are presented along with the microparticles $\mathrm{Mp}$ in Figures 5 and 6 . Samples were also collected along wall $\mathrm{C}$ of pit 1 for analysis of oxygen isotopic abundances $\delta^{18} \mathrm{O}$. The small sampling interval $(0.02 \mathrm{~m})$ yielded up to 15 samples $\left(\mathrm{C}, \mathrm{Mp}, \mathrm{\delta}^{18} \mathrm{O}\right)$ per annual accumulation increment for thicker units which results in the detection of individual storm events. To eliminate sporadic noise the microparticle and conductivity data have been smoothed (Figs.5 and 6) using an unweighted three-sample running mean. The natural isotopic diffusion within the firn produces a very smooth annual signal in the $\delta^{18} \mathrm{O}$ record. Each sample was collected with respect to stratigraphy allowing investigation of the relationship between these constituents and visual stratigraphic features.

Below one meter the annual microparticle concentration signal is well preserved. Above this level the signal is weak and poorly defined although detectable when the data are smoothed (Figs.5 and 6). This enhancement of the annual signal with depth may reflect post-depositional concentration as the insoluble particles remain in situ while vapor diffuses within the firn. The microparticle concentration peak is not consistently associated with an individual stratigraphic feature in the annual unit although in most years the peak appears slightly above the bonded-grain crust in the homogeneous fine-grained material. There are exceptions when the peak is directly associated with the m11/bgc complex (e.g. 1972, wall C, Fig.6). Except in the upper meter of firn, the variations in microparticle concentration exhibit a distinct seasonal cycle thus providing a tool for dating the firn and constructing annual mass accumulation records.

Samples with higher liquid conductivities are more frequently associated with the m11/bgc boundaries although exceptions exist here as well (e.g. 1974 and 1973, wall A, Fig.5). The conductivity record contains more single sporadic values than the microparticle profile which may reflect individual storm events (higher $\mathrm{NaCl}$ ) or contamination of the sample. Nevertheless, the smoothed conductivity profiles show excellent correspondence with the stratigraphic time scale.

The oxygen isotope abundance $\delta^{18} \mathrm{O}$ (the ratio of heavier ${ }^{18} \mathrm{O}$ to lighter ${ }^{16} \mathrm{O}$ ) exhibits a smooth, well-preserved seasonal cycle (Fig.6) except for the 1980 peak. In each unit, except 1980, the isotopically heavier samples are associated with the $\mathrm{mll} / \mathrm{bgc}$ complex, the same relationship reported by Epstein and others (1965). The mechanisms by which the isotopic signal is preserved and smoothed within the firn are not well understood although Whillans and Grootes (1985) present a model which appears to explain the observed $\delta^{18} \mathrm{O}$ profiles in both Greenland and at Dome C, East Antarctica but not the South Pole $\delta^{18} \mathrm{O}$ record. Johnsen (1977) has demonstrated that the seasonal $\delta^{18} \mathrm{O}$ signal will be smoothed gradually by diffusion of the water molecules during the firnification process. Recent analysis of deuterium in South Pole pits and shallow cores (Jouzel and others 1979) reveals that this smoothing effect is not as rapid as predicted by Johnsen. Inspection of the $\delta^{18} \mathrm{O}$ profile (Fig.6) reveals a diversity in the annual range but over the 11 a period no gradual systematic smoothing is evident. The $\delta^{18} \mathrm{O}$ range for the 1981-82 unit (Fig.6) is $12 \%$ and for $1971-72$ unit is $10 \%$. Aldaz and Deutsch (1967) report an average seasonal range of $14 \%$ in precipitation collected at the South Pole. The seasonal $\delta^{18} \mathrm{O}$ signal will eventually be smoothed beyond resolution but at the 


\section{South Pole, 1982, Pit I, Wall A}

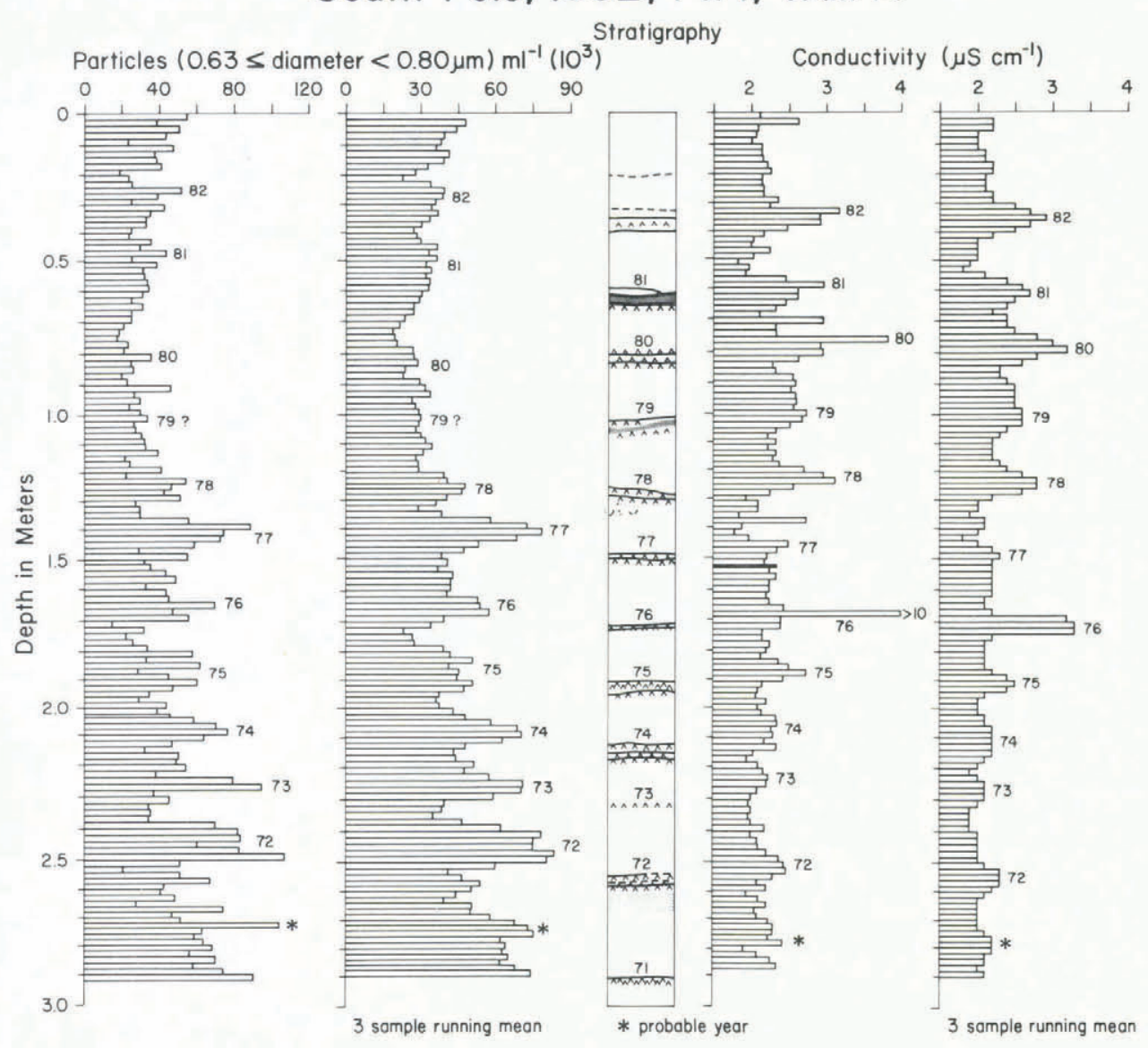

Fig.5. Pit 1, wall A, data presented from left to right include: (1) the concentration of microparticles with diameters between 0.63 and $0.80 \mu \mathrm{m} \mathrm{ml^{-1 }}$ of sample; both original data and three-sample running means are presented, (2) the vertical stratigraphic section from wall A (Fig.2) where these samples were collected, (3) liquid conductivity in $\mu \mathrm{S} \mathrm{cm}^{-1}$ for the same sampling interval as the microparticle data; both original and three-sample running means are presented. The dates for each profile were inferred from the seasonal signal in that record. The asterisk indicates a probable year for which data are inconclusive and uninterpretable features are marked (?).

South Pole it appears fairly well preserved over 25 a and possibly up to 100 a (Jouzel and others 1983).

An interesting observation in the oxygen isotopic record is the smoothing of the 1980 feature which appears as a shoulder on the 1981 peak. Although insufficient data are available to substantiate this supposition, a working hypothesis is that the absence of an impermeable bonded-grain crust on top of the 1980 mass loss layer allowed vapor diffusion and isotopic homogenization across the annual boundary. Although bonded-grain crusts frequently cap the mass loss layers they are not always present. If the bonded-grain crust is a prerequisite for preservation of the seasonal isotopic signal, this would detract from its utility for dating shallow ice cores. Certainly a more thorough investigation of the relationship between the stratigraphy and the $\delta^{18} \mathrm{O}$ record is warranted.

Inspection of Figures 5 and 6 leads to the general conclusion that most precise dating will be accomplished when numerous snow parameters are analyzed. Even with the visual stratigraphy, microparticles, conductivity and $\delta^{18} \mathrm{O}$, it is impossible to conclude definitively whether a year has been missed between 1971-72 in pit 1, wall C (Fig.6). The thick, low-density zone suggests intense metamorphism which may or may not have disturbed the annual signals. No visible boundary feature was observed in the unit which was at the very bottom of the pit where it is most difficult to work and lighting is more restricted. The beta-radioactivity, conductivity and microparticle data reflect an annual boundary which is absent both visually and in the $\delta^{18} \mathrm{O}$ record. If the annual boundary complex was destroyed by post-depositional processes, then the annual $\delta^{18} \mathrm{O}$ signal may have diffused over adjoining annual units. Obviously this problem is insolvable without the 1964-65 beta-activity horizon which will be established in the core drilled behind wall C. For strata older than 1954 (the first major beta horizon) this type of inconsistency may be unresolvable using present techniques and prevent establishment of an absolute time scale. Nevertheless, because of the good temporal resolution and preservation of distinct annual signals in some parameters within the firn, South Pole probably represents an excellent site for obtaining a long paleoclimatic ice-core record in East Antarctica.

\section{CONCLUSIONS}

Stratigraphic studies, conducted in great detail over large areas of pit wall, support the following conclusions: (1) the variability in accumulation for any year(s) may be substantial ( $100 \%$ or more) over distances as short as $3 \mathrm{~m},(2)$ inferences about regional trends in precipitation from an accumulation record reconstructed at one site are probably correct only when averaging intervals are long enough to smooth topographic effects, and (3) the presence of either an unusually thick mass loss layer or a sequence of multiple mass loss layer/bonded-grain crust complexes does not necessarily reflect a year of missing accumulation. The analysis of microparticle concentrations, liquid conductivity, and oxygen isotopic abundances indicate the following: (1) microparticle concentrations exhibit a well-preserved 


\section{South Pole, 1982, Pit I, Wall C}

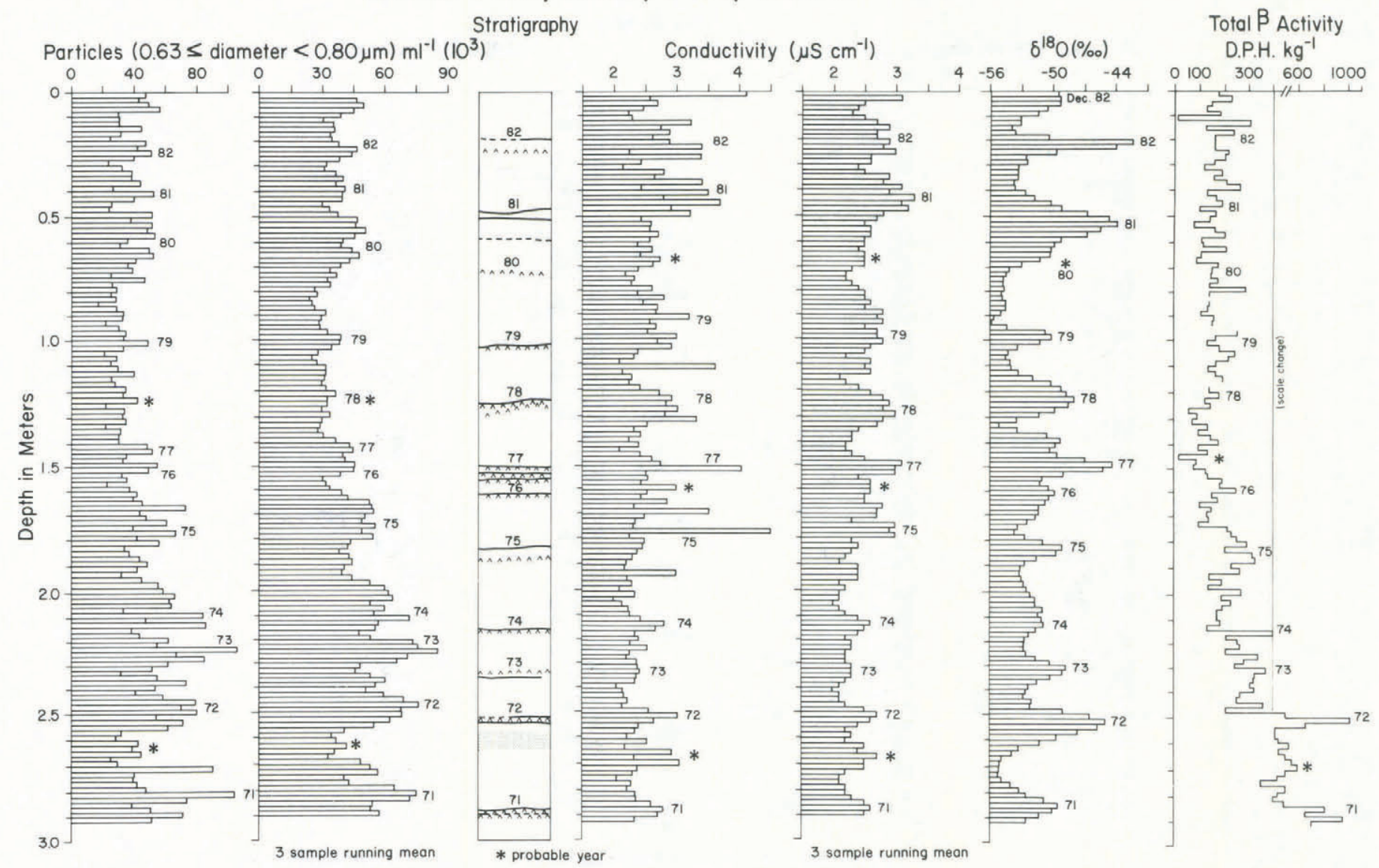

Fig.6. Pit 1, wall C, data presented from left to right include: (1) the concentration of microparticles with diameters between 0.63 and $0.80 \mu \mathrm{m} \mathrm{ml} \mathrm{m}^{-1}$ of sample; both original data and three-sample running means are presented, (2) the vertical stratigraphic section from wall $C$ (Fig.2) where these samples were collected, (3) liquid conductivity in $\mu S \mathrm{~cm}^{-1}$ for the same sampling interval as the microparticle data; both original and three-sample running means are presented, (3) the oxygen isotopic ratio $\left({ }^{18} \mathrm{O} /{ }^{16} \mathrm{O}\right)$ in $\%$, and (4) beta-radioactivity in disintegrations $\mathrm{kg}^{-1} \mathrm{~h}^{-1}$. The dates for each profile were inferred from the seasonal signal in that record except for the beta profile dated by visible stratigraphy. The asterisk indicates a probable year for which data are inconclusive.

seasonal cycle below $1 \mathrm{~m}$ which may reflect amplification of the annual signal during the firnification process, (2) liquid conductivity varies seasonally but the signal may be damped by vapor diffusion deeper in the firn, (3) the $\delta^{18} \mathrm{O}$ abundance exhibits a distinct seasonal cycle and the smoothing of the signal does not appear constant nor rapid with depth, and (4) preservation of the seasonal signal in $\delta^{18} \mathrm{O}$ may depend upon the existence of an impermeable bonded-grain crust in association with the annual boundary, but this latter hypothesis requires further investigation.

\section{ACKNOWLEDGEMENTS}

We gratefully acknowledge Mary Davis for the laboratory analysis of the microparticles and conductivities, Thomas Bain for his participation in the field program and Robert Tope for production of the illustrations. This work was support by NSF grant DPP-8018860.

\section{REFERENCES}

Aldaz L, Deutsch S 1967 On a relationship between air temperature and oxygen isotope ratio of snow and firn in the South Pole region. Earth and Planetary Science Letters 3: $267-274$

Bader H, Haefeli R, Bucher E, Neher J, Eckel O, Thams C 1939 Der Schnee und seine Metamorphose. Beiträge zur Geologie der Schweiz. Geotechnische Serie. Hydrologie 3 [English translation: Snow and its metamorphism. SIPRE Translation 14, 1954]
Benson C S 1971 Stratigraphic studies in the snow at Byrd station, Antarctica, compared with similar studies in Greenland. Antarctic Research Series 16: 333-353

Black H P, Budd W 1964 Accumulation in the region of Wilkes, Wilkes Land, Antarctica. Journal of Glaciology 5(37): $3-15$

Colbeck S C 1983 Theory of metamorphism of dry snow. Journal of Geophysical Research 88(C9): 5475-5482

Crozaz G 1969 Fission products in Antarctic snow. An additional reference level in January 1965. Earth and Planetary Science Letters 6(1): 6-8

Epstein S, Sharp R P, Gow A J 1965 Six-year record of oxygen and hydrogen isotope variations in South Pole firn. Journal of Geophysical Research 70(8): 1809-1814

Giovinetto M B, Schwerdtfeger W 1966 Analysis of a 200 year snow accumulation time series from the South Pole. Archiv für Meteorologie, Geophysik und Bioklimatologie Ser A 15(2): 227-250

Gow A J 1965 On the accumulation and seasonal stratification of snow at the South Pole. Journal of Glaciology 5(40): 467-477

Gow A J, Rowland R 1965 On the relationship of accumulation to surface topography at "Byrd station", Antarctica. Journal of Glaciology 5(42): 843-847

Johnsen S J 1977 Stable isotope homogenization of polar firn and ice. International Association of Hydrological Sciences Publication 118 (General Assembly of Grenoble 1975 - Isotopes and Impurities in Snow and Ice): 210-219

Jouzel J, Pourchet M, Lorius C, Merlivat L 1979 Artificial tritium fall-out at the South Pole. Vienna, International Atomic Energy Agency (Report SM-232-238) 
Jouzel J, Merlivat L, Petit J R, Lorius C 1983 Climatic information over the last century deduced from a detailed isotopic record in the South Pole snow. Journal of Geophysical Research 88(C4): 2693-2703

Koerner R M 1971 A stratigraphic method of determining the snow accumulation rate at Plateau station, Antarctica, and application to South Pole-Queen Maud Land traverse 2, 1965-1966. Antarctic Research Series 16: 225-238

Kuivinen K C 1983 A 237-meter ice core from South Pole Station. Antarctic Journal of the United States 18(5): 113-114

Kuivinen K C, Koci B R, Holdsworth G W, Gow A J 1982 South Pole ice core drilling, 1981-1982. Antarctic Journal of the United States 17(5): 89-91

Lambert G, Ardouin B, Sanak J, Lorius C, Pourchet M 1977 Accumulation of snow and radioactive debris in Antarctica: a possible refined radiochronology beyond reference levels. International Association of Hydrological Sciences 118 (General Assembly of Grenoble 1975 Isotopes and Impurities in Snow and Ice): 146-158

Mosley-Thompson E, Thompson L G 1982 Nine centuries of microparticle deposition at the South Pole. Quaternary Research 17(1): 1-13

Mosley-Thompson E, Thompson L G 1983 South Pole ice core processing and microparticle analysis. Antarctic Journal of the United States 18(5): 118-119

Mosley-Thompson E, Kruss P D, Bain T 1983 South Pole pit stratigraphic studies. Antarctic Journal of the United States 18(5): 116-118

Pourchet M, Pinglot F, Lorius C 1983 Some meteorological applications of radioactive fallout measurements in Antarctic snows. Journal of Geophysical Research 88(C10): 6013-6020

Schytt V 1958 Glaciology II. Norwegian-British-Swedish Antarctic Expedition, 1949-1952. Scientific Results 4

Scott R F 1905 The voyage of the Discovery. 2 vols. London, Smith, Elder and Co.

Sorge E 1935 Glaziologische Untersuchungen in Eismitte. Wissenschaftliche Ergebnisse der Deutschen Gronland-Expedition Alfred Wegener 1929 und 1930/31 3: $62-270$

Stauffer B, Schwander J 1983 Core processing and analysis of ice cores drilled at the South Pole. Antarctic Journal of the United States 18(5): 114-116

Taylor L D 1971 Glaciological studies on the South Pole traverse, 1962-1963. Antarctic Research Series 16: 209-224

Thompson L G 1977 Microparticles, ice sheets and climate. Ohio State University. Institute of Polar Studies. Report 64

Whillans I W, Grootes P M In press Isotopic diffusion in cold snow and firn. Journal of Geophysical Research 